DOI: https://doi.org/10.35699/2238-037X.2019.13534

\title{
REFLEXÕES SOBRE O TRABALHO EM FRIGORÍFICOS E SEUS IMPACTOS SOBRE A SAÚDE DOS TRABALHADORES ${ }^{1}$
}

\author{
Reflections on Labor in Slaughterhouses and its Impacts on Workers' Health
}

\author{
MARRA, Gabriela Chaves ${ }^{2}$ \\ COHEN, Simone Cynamon ${ }^{3}$ \\ CARDOSO, Telma Abdalla de Oliveira ${ }^{4}$
}

\section{Resumo}

O artigo discute como a intensificação do trabalho e a forma de executar as tarefas nos frigoríficos tem implicações na saúde dos trabalhadores. Buscou-se articular este tema com elementos conceituais que expliquem a realidade do trabalho em frigoríficos. A pesquisa qualitativa teve como suporte a concepção teórico-metodológica de Marx e como questão central a produção. A expressão atual da indústria da carne corresponde ao processo capitalista de produção norteado pela lógica do agronegócio, acarretando sobrecarga no trabalho e adoecimento dos trabalhadores do setor frigorífico. A busca pela manutenção do agronegócio e acumulação de capital encobre a exploração e desgaste no trabalho e o adoecimento dos trabalhadores.

Palavras-chave: Frigorífico. Intensificação do trabalho. Modo capitalista de produção.

\section{ABstract}

The article discusses how labor intensification and the way tasks are executed in slaughterhouses have implications on the workers' health. This issue is articulated with conceptual elements that reveal the reality in slaughterhouses. The qualitative research adopted Marx's theoretical-methodological framework and the central focus of the investigation was production. The current expression of meat industry corresponds to the capitalist process of production guided by the logic of agribusiness, leading to labor overload and sickness of those who work in slaughterhouses. The efforts to maintain agribusiness and capital accumulation hides labor exploitation and sickness of workers.

Keywords: Slaughterhouse. Work Intensification. Capitalist production method.

\footnotetext{
${ }^{1}$ Este artigo é resultante da tese de doutoramento de Gabriela Chaves Marra, na Escola Nacional de Saúde Pública, Fiocruz, bolsista da Fundação de Amparo à Pesquisa do Estado do Rio de Janeiro (Faperj).

${ }^{2}$ Doutoranda em Saúde Pública pelo Programa de Saúde Pública, da Escola Nacional de Saúde Pública, da Fundação Oswaldo Cruz (Ensp/Fiocruz); Mestre em Saúde Pública pela Ensp, Fiocruz; graduação em Medicina Veterinária pela Universidade Federal Rural do Rio de Janeiro (UFRRJ). Médica Veterinária, integra a equipe de pesquisa do Núcleo de Biossegurança, Ensp, Fiocruz. E-mail: gabicmarra@uol.com.br.

${ }^{3}$ Doutora em Saúde Pública pela Escola Nacional de Saúde Pública, da Fundação Oswaldo Cruz (Ensp/Fiocruz); Mestre em Saúde Pública pela Ensp, Fiocruz; graduação em Arquitetura pela Universidade Santa Úrsula. Arquiteta, professora e pesquisadora sênior da Ensp, Fiocruz. E-mail: cohen@ensp.fiocruz.br.

${ }^{4}$ Doutora em Saúde Pública pela Escola Nacional de Saúde Pública, da Fundação Oswaldo Cruz (Ensp/Fiocruz); Mestre em Ciência da Informação pela Universidade Federal do Rio de Janeiro (UFRJ); graduação em Medicina Veterinária pela Universidade Federal de Minas Gerais (UFMG). Médica Veterinária, professora e pesquisadora sênior do Núcleo de Biossegurança, Ensp, Fiocruz. E-mail: abdalla.telma@gmail.com.
}

Trabalho \& Educação | v.28 | n.2 | p.231-243 | maio-ago | 2019 


\section{INTRODUÇÃO}

Este artigo objetiva discutir a intensificação do trabalho e o modo como as tarefas são executadas nos frigoríficos e suas implicações para a saúde dos trabalhadores. Buscou-se abordar este tema de forma articulada com os elementos conceituais que expliquem a realidade do trabalho em frigoríficos. Tomando como ponto inicial os sujeitos reais, os trabalhadores, e sua condição material de existência, o trabalho, analisados por via empírica, faz-se, num plano teórico, uma aproximação dos aspectos mais simples aos mais complexos para revelar o essencial do todo.

Esse essencial pode ser entendido como a relação saúde/doença do trabalhador, dentro do contexto das condições atuais de trabalho nos frigoríficos. O alcance da compreensão da sua totalidade, aqui, não implica em considerar o conhecimento extensivo de todas as suas relações, mas considera a dialética da condição de classe trabalhadora inserida nas relações capitalistas. Desse modo, este artigo teve como suporte a concepção teórico-metodológica de Marx, pois entende-se que o trabalho ocupa um papel central na análise das condições de saúde dos trabalhadores.

A questão do trabalho para o trabalhador é compreendida como uma atividade de socialização, de humanização e que garante a reprodução social. Através do trabalho, o homem cria condições para sua existência, contudo, atravessado por conflitos entre o interesse individual e o coletivo, consequência da condição de classe e da divisão do trabalho. Divisão essa, que separa o trabalho industrial e comercial, de um lado, e o trabalho agrícola, de outro, e, com isso, separa a cidade do campo, colocando-os em oposição de interesses (MARX, ENGELS, 2007).

Na obra "A Ideologia Alemã", Marx e Engels (2007), partem do pressuposto que a observação dos fatos reais e suas verdadeiras relações devem demonstrar, objetivamente, a conexão entre a estrutura social e política e a produção.

[...] a produção de ideias, de representações, da consciência, está, em princípio, imediatamente entrelaçada com a atividade material e com o intercâmbio material dos homens, com a linguagem da vida real (MARX, ENGELS, 2007, p. 94).

As considerações de Marx (2011) na introdução da obra "Para a crítica da economia política" sintetizam as bases de seu método:

Parece ser correto começarmos pelo real e pelo concreto, pelo pressuposto efetivo, e, portanto, no caso da economia, por exemplo, começarmos pela população, que é o fundamento e o sujeito do ato social de produção como um todo. Considerado de maneira mais rigorosa, entretanto, isso se mostra falso. A população é uma abstração quando deixo de fora, por exemplo, as classes das quais é constituída. Essas classes, por sua vez, são uma palavra vazia se desconheço os elementos nos quais se baseiam. P. ex., trabalho assalariado, capital etc. Estes supõem troca, divisão do trabalho, preço etc. O capital, p. ex., não é nada sem o trabalho assalariado, sem o valor, sem o dinheiro, sem o preço etc. Por isso, se eu começasse pela população, esta seria uma representação caótica do todo e, por meio de uma determinação mais precisa, chegaria analiticamente a conceitos cada vez mais simples; do concreto representado [chegaria] a conceitos abstratos [Abstrakta] cada vez mais finos, até que tivesse chegado às determinações mais simples. Daí teria de dar início à viagem de retorno até que finalmente chegasse de novo à população, mas desta vez não como a representação caótica de um todo, mas como uma rica totalidade de muitas determinações e relações (MARX, 2011, p. 76-77). 
Na obra "Do socialismo utópico ao socialismo científico", Engels (2011, p. 95) escreve que na

concepção materialista da história a produção e a troca de mercadorias, é a base de toda a ordem social. Em todas as sociedades a distribuição dos produtos, e a divisão social dos homens em classes é determinada pelo que a sociedade produz e como produz o pelo modo de trocar os seus produtos.

Podemos dizer, então, que toda sociedade tem como suporte forças produtivas e relações de produção características constituídas social e historicamente, formando a estrutura econômica da sociedade. Assim, as bases para as transformações sociais e para o desenvolvimento econômico da sociedade são as mudanças dos modos de produção e de troca de determinada época. Marx (2008) descreve no "Prefácio à Contribuição à crítica da economia política" o que ele diz ser o fio condutor de seu estudo:

na produção social da sua vida os homens entram em determinadas relações, necessárias, independentes da sua vontade, relações de produção que correspondem a uma determinada etapa de desenvolvimento das suas forças produtivas materiais (MARX, 2008, p. 47).

O conceito de produção de Marx é mediada pelo consumo, distribuição e troca.

A produção é determinada por leis gerais da natureza; a distribuição resulta da contingência social e, por isso, pode exercer uma ação mais ou menos estimulante sobre a produção; a troca situa-se entre ambas, como um movimento formalmente social; o ato final do consumo, que é concebido não apenas como resultado, mas também como objetivo finai, situa-se, a bem dizer, fora da economia, a não ser quando, por sua vez, reage sobre o ponto de partida para iniciar um novo processo (MARX, 2011, p. 62).

A capacidade humana de produzir as condições de sua própria existência através do trabalho, produzindo mercadorias é a base material da sociedade, e depende do processo de trabalho. Marx destaca o processo de trabalho como, "em primeiro lugar, a atividade orientada a um fim, ou o trabalho propriamente dito; em segundo lugar, seu objeto e, em terceiro, seus meios" (MARX, 2011, p. 328).

\section{O tRABALHO E O AGROONEGócio}

As relações de produção junto com as forças produtivas compõe o modo capitalista de produção. $\mathrm{O}$ agronegócio opera com base em monopólio de recursos naturais, que independem de investimentos ou da aplicação do trabalho humano para produzi-las. Esses recursos, submetidos à exploração intensiva ou extensiva, derivada da demanda por mercadorias, produzem rendas fundiárias, que são objeto disputa no processo de apropriação da renda e da riqueza social (DELGADO, 2010). Na indústria pecuária, o objeto de trabalho é dado em conexão direta com a natureza, o animal.

Animais e plantas, que se costumam considerar como produtos naturais, são, em sua presente forma, não apenas produtos de um trabalho anterior, mas o resultado de uma transformação gradual, realizada mediante o trabalho humano (DELGADO, 2010, p. 331).

Para Marx (2017), o processo de trabalho é atividade orientada a um fim, apropriação do elemento natural para satisfazer as necessidades humanas, interação entre homem e natureza, condição natural da vida humana, comum a todas as suas formas sociais. 
Mas no processo de trabalho, o trabalhador está sob o controle do capitalista; não é dono dos meios de produção; vende sua força de trabalho não pelo valor que irá produzir, mas pelo salário. Assim, Marx demonstra a relação entre a propriedade privada dos meios de produção, força de trabalho e mais-valor.

O processo de produção pressupõe que os homens estabeleçam relações entre si para que possibilitem determinada forma de produzir, as relações de produção, que incluem as formas de apropriação da natureza e dos produtos do trabalho. Mas, Delgado (2010) pondera que o processo de produção se desencadeia pelo progresso técnico. A maior ou menor produção vai depender da extração de mais valor, do grau de exploração e das relações que se dão entre as classes num determinado modo de produção.

É importante ressaltar que o movimento histórico que transforma os produtores em trabalhadores assalariados, vendendo sua força de trabalho, não pode ser apenas observado do ponto de vista do trabalhador de sexo masculino, mas do ponto de vista da posição social das mulheres na produção da força de trabalho. Desta forma a acumulação de capital é, sobretudo, "uma acumulação de diferenças, desigualdades, hierarquias e divisões que separaram os trabalhadores entre si” (FEDERICI, 2017, p. 232).

Marx (2017) ressalta que com a introdução da maquinaria aumenta o material humano sujeito à exploração pelo capital e o grau de exploração ao se apropriar da força de trabalho feminina e infantil.

O trabalhador produz mais valor do que o valor que a força de trabalho custa ao capitalista, e este mais valor é apropriado por quem é dono dos meios de produção. A exploração da força de trabalho concentra o excedente de valor extraído do trabalho. $O$ mais-valor é exatamente o valor que é gerado pelo trabalho, mas que não é repassado para o trabalhador. Essa relação entre o sujeito capitalista e o trabalhador é característica do modo capitalista de produção, que explora o trabalhador.

[...] o regime capitalista de produção e a exploração do operário, que dele se deriva, tinham por forma fundamental a apropriação de trabalho não pago; que o capitalista, mesmo quando compra a força de trabalho de seu operário por todo o seu valor, por todo o valor que representa como mercadoria no mercado, dela retira sempre mais valor do que the custa e que essa mais valia é, em última análise, a soma de valor de onde provém a massa cada vez maior do capital acumulado em mãos das classes possuidoras (ENGELS, 2011, p. 93-94).

O mais-valor é, portanto, todo trabalho não remunerado, apresentado sob a forma de mais-valor absoluto, quando aumenta a quantidade de horas de trabalho sem aumentar a remuneração; e mais-valor relativo, quando o capitalista investe em tecnologia e em maquinário, com isso aumenta a produção. Dentro do processo de trabalho somente a força de trabalho tem a capacidade de produzir um valor maior do que ela possui (MARX, 2017).

No contexto brasileiro, observamos o avanço do agronegócio para manter a acumulação capitalista. O agronegócio opera com base em monopólio de recursos naturais, que precedem investimentos ou da aplicação do trabalho humano para produzi-las. Esses recursos, submetidos à exploração intensiva ou extensiva, derivada da demanda por mercadorias, produzem rendas fundiárias, que são objeto de disputa no processo de apropriação da renda e da riqueza social (DELGADO, 2010). 
A exploração da força de trabalho, no modo capitalista de produção, expressa a contradição estrutural de dada forma de sociabilidade que, ao mesmo tempo em que precisa do trabalho para sua reprodução, necessita explorá-lo ao extremo, impondo-lhe o sentido mais profundo de sua mercantilização em favor do capital (ANTUNES, PRAUN, 2015).

\section{A INDÚSTRIA DA CARNE}

Importante destacar que, embora, a maior parte dos produtos do abate do gado bovino seja destinada ao consumo interno brasileiro, as estatísticas produzidas pelo governo sobre o setor industrial da carne dão ênfase aos dados sobre exportação. Isso pode ser explicado pela importância que o Brasil tem no mercado mundial de carnes, estando entre os principais produtores e exportadores (CARVALHO, 2018).

O processamento de carne bovina começa com o transporte dos animais até o frigorífico, onde é feito o abate, processamento e distribuição. Os estabelecimentos de carnes e derivados são classificados em abatedouro frigorífico e unidade de beneficiamento de carne e produtos cárneos (BRASIL, 2017). O termo indústria da carne se refere a pecuária industrializada para produção, embalagem, frigorificação e comercialização de carne.

Inaugurada em Chicago, a indústria da carne, como se conhece atualmente, trouxe mudanças na organização do trabalho. Um modelo que marcou o uso de esteiras rolantes e nórias, mecanização, trabalho fragmentado, medido e padronizado (DIAS, 2009). Novas técnicas, instrumentos e procedimentos de abate foram introduzidos. Essa divisão do trabalho amplia a produtividade como instrumento de intensificação do processo acumulativo, devido ao nível de desenvolvimento de capital constante (equipamentos e tecnologia). Ao invés da expansão da contratação (capital variável), que é a força de trabalho, são as máquinas que aumentam a produtividade mesmo com menos trabalhadores. Assim, produz-se mais mercadorias num menor espaço de tempo. "[...] as condições técnicas do próprio processo de produção, a maquinaria, os meios de transporte etc. possibilitam, em maior escala, a transformação mais rápida de mais-produto em meios de produção suplementares" (MARX, 2017, p. 858).

No Brasil, como em boa parte da Europa, a concepção atual de frigorífico surgiu em função de preocupações sanitaristas e higienistas. A maioria das grandes cidades criou seu matadouro municipal para eliminar o trânsito de animais, o mau cheiro, o sangue e o barulho (BOSI, 2014a). Fez-se do negócio da carne um espaço apartado, mantendo à distância a sujeira, a doença, a violência e a exploração (DIAS, 2009).

Um tema comum que vinculava a construção dos matadouros municipais fora dos limites das cidades, era tornar não visível a matança dos animais para a população (FITZGERALD, 2010).

A disposição dos frigoríficos, aprofundando a separação entre local de abate e local de consumo, de meados do século XIX a meados do século XX, distanciou a matança do local de consumo.

Segundo Dias (2009), há uma dissociação entre animal e carne, mas que só será obtida plenamente no processo industrial. Esse mesmo processo teve como um de seus alvos o ocultamento gradual de toda a violência, contra homens e animais. 
Os matadouros públicos ficavam dentro da área urbana, e as práticas de matança eram consideradas insalubres. O primeiro matadouro da cidade do Rio de Janeiro, o matadouro de Santa Luzia, ficava próximo à praia. Com o crescimento da cidade e obsolescência desse matadouro, foi construído provisoriamente o matadouro de São Cristóvão, que permaneceu por quase trinta anos em área de grande circulação de pessoas, no centro, onde está hoje a Praça da Bandeira (DIAS, 2009). Como ação política para melhorar o abastecimento de carne no Rio de Janeiro foi criado um novo matadouro na região de Santa Cruz (SANTOS, 2011).

Em São Paulo ocorre algo semelhante, o Matadouro Público é deslocado para além dos limites da cidade. O novo matadouro foi construído em 1852, distante da área urbana e ficando sujeito a um código sanitário mais rigoroso, que exigia instalações higiênicas e exame médico de cada animal (SHINYASHIKI, SOUZA, SALGADO, 2007).

No início do século XX, Barretos, no interior paulista, veio a configurar o pólo industrial no comércio de carnes.

No Rio Grande do Sul, na mesma época, as charqueadas produziam carne seca e salgada, além de couro para exportação. $O$ regime de trabalho nas charqueadas era de longa duração e de exploração do trabalho coletivo, e a apropriação dos lucros do capital favorecia somente o charqueador (MOREIRA, 2007). As exigências de segurança nas charqueadas não consistiam em prioridade; demonstrando mais do que uma negligência administrativa, mas também o desconhecimento da necessidade de assistência técnica e o baixo investimento na charqueada gaúcha (MOREIRA, 2007).

A Armour foi o primeiro matadouro a construir a câmara frigorífica no final da década de 1870, nos Estados Unidos. Esta indústria expandiu seus domínios para o sul do continente por meio da compra de charqueadas e matadouros no Rio Grande do Sul, devido ao decreto do governo estadual que estabelecia isenção de impostos sobre os produtos exportados por um prazo de 30 anos (DIAS, 2009). Assim, em 1903, ocorreram as primeiras iniciativas quanto ao processamento de carnes no Brasil (BOSI, 2014b).

Investimentos em tecnologia elevaram a produtividade e a qualidade do gado bovino brasileiro, tornando-o competitivo e alcançando o mercado mundial. Conforme o Instituto Brasileiro de Geografia e Estatística, grande parte dos animais é criada em pastagens, cuja área chega a 111.775.274 hectares, em todo território brasileiro (BRASIL, 2017). A remoção da cobertura vegetal para formar as pastagens para a criação de animais tem impactos negativos no ambiente. A expansão agrícola adota pacotes tecnológicos, e exerce um consumo crescente de recursos naturais como solos, água, biodiversidade, florestas nativas, luminosidade, condições climáticas (DELGADO, 2010).

Com efeito, a cadeia produtiva da carne resulta em um quadro negativo sobre a saúde e o modo de vida da população, exploração do trabalho e contaminação ambiental. As condições de trabalho continuam as mesmas apesar do desenvolvimento das forças produtivas.

Tanto matadouros, quanto açougues e charqueadas revelavam as condições degradantes de trabalho as quais eram impostas aos trabalhadores. Essas relações de produção fazem parte da estrutura econômica, como afirma Marx (2008, p. 47): "[...] a verdadeira base da sociedade: é o alicerce sobre o qual se ergue a superestrutura 
jurídica e política e ao qual correspondem formas definidas de consciência social". Isso significa que os modos de produção de uma formação social, em dado momento, são base da sociedade na sua organização jurídica e política. Embora, numa nova fase do desenvolvimento de forças produtivas materiais, a indústria carne não alterou de maneira significativa as relações de produção no que tange a exploração do trabalho e os agravos à saúde dos trabalhadores.

Upton Sinclair, jornalista e escritor norteamericano, elaborou uma reflexão crítica e sistemática sobre a situação de trabalho em matadouros. O livro, The Jungle (A Selva), publicado em 1906 (SINCLAIR,1981), conta a história de uma família de imigrantes lituanos que vão trabalhar no complexo fabril da carne. Nele o autor denuncia as condições de vida e de trabalho degradantes dos operários de uma indústria de carne em Chicago. As condições da indústria de carne relatadas por Sinclair, impulsionou o estabelecimento de uma lei de inspeção de carnes e uma lei abrangente sobre alimentos e medicamentos que criou o Food and Drug Administration (FDA, 2018). Porém a situação dos trabalhadores permanecia invisível.

Segundo Rifkin (1992), Henry Ford ao observar o processo de trabalho nos matadouros de Chicago, que ordenava e engrenava o trabalho de centenas de homens e mulheres, inspirou-se para elaborar um modelo para a organização do trabalho e da produção em massa nas indústrias que surgiam. O sistema apresentado por Ford, mostrava a divisão de tarefas, em linha continua, com o auxílio de esteiras, de produção padronizada e em larga escala. Este modelo transformou a produção e intensificou-a. "O trabalho humano passa a ser mínimo, requerendo, mais que habilidade, a racionalização do tempo e do movimento" (DIAS, 2009, p. 25).

A banalização da vida dos trabalhadores também é tema da peça teatral "Santa Joana dos Matadouros" de Bertolt Brecht. A peça retrata a vida dos trabalhadores nos frigoríficos de Chicago. A trama acontece durante a crise econômica e social iniciada com a quebra da bolsa em 1929. Entre os personagens estão a massa trabalhadora, os desempregados, os donos das grandes indústrias da carne e especuladores. Há nos trabalhadores uma natureza contraditória que é explorada ao longo da peça. $\mathrm{O}$ salário insuficiente e o trabalho degradante os fazem reivindicar por melhores condições e ao mesmo tempo a familiaridade com os meios de produção e o desespero por perder o emprego os fazem continuar no trabalho.

A expressão atual da produção na indústria da carne corresponde ao processo capitalista de produção. A separação entre o produto do trabalho e o próprio trabalho é a transformação da riqueza material (as mercadorias) em capital por meio do trabalho. O trabalhador não é dono do que produz (MARX, 2017).

Essa condição faz com que o trabalhador não se identifique com o trabalho, ele vende sua força de trabalho em troca do salário, além disso a fragmentação do trabalho no capitalismo leva cada vez mais a especialização das tarefas. Nas "linhas de produção" características dos frigoríficos, o trabalho não só é especializado como inscreve no corpo do trabalhador o sofrimento físico e mental.

[...] o trabalhador sai do processo sempre como nele entrou: como fonte pessoal de riqueza, porém despojado de todos os meios para tornar essa riqueza efetiva para si. Como antes de entrar no processo seu próprio trabalho já está alienado dele, apropriado pelo capitalista e incorporado ao capital, esse trabalho se objetiva continuamente, no decorrer do processo, em produto alheio. Sendo processo de produção e, ao mesmo tempo, processo de consumo da força de trabalho pelo capitalista, o produto do 
trabalhador transforma-se continuamente não só em mercadoria, mas em capital, em valor que suga a força criadora de valor, em meios de subsistência que compram pessoas, em meios de produção que se utilizam dos produtores (MARX, 2017, p.786).

\section{INSTITUCIONALIZAÇÃO DA SANIDADE ANIMAL E A INTENSIFICAÇÃO DO TRABALHO NA PRODUÇÃO DA CARNE}

Os esforços para proteger os consumidores e a criação de leis, nos diversos países, voltadas à sanidade animal, além da abertura de novos mercados para o setor agropecuário, tornaram imprescindível o estabelecimento no Brasil de mecanismos de inspeção para impulsionar as transações comerciais.

O Estado teve de estar presente na institucionalização do setor carne. Várias normas foram estabelecidas para atender as empresas frigoríficas e moldar o atual Serviço de Inspeção Federal/SIF, do Ministério da Agricultura Pecuária e Abastecimento. Em 1915 a regulamentação específica da inspeção sanitária de carnes foi expedida por meio do Decreto $n^{\circ} 11.462$ regulamentando o "Serviço de Inspecção de Fábricas de Productos Animais" (PARDI, 1996).

Em 1933, houve a regulamentação da profissão do Médico Veterinário e em 1934 a aprovação do Regulamento da Inspeção Federal de Carnes e Derivados e a Inspeção de Leite e derivados, através dos Decretos n² 24.550 e 24.549.

Em 1950, tornou-se obrigatória a inspeção industrial e sanitária, de todos os produtos de origem animal. Esta legislação atribuiu a responsabilidade da execução da inspeção aos governos federal, estadual e municipal, de acordo com o âmbito do comércio atendido pelo estabelecimento (BRASIL, 1950).

Em 1952, o Decreto n 30.691 estabeleceu o Regulamento da Inspeção Industrial e Sanitária de Produtos de Origem Animal (RIISPOA). Este Regulamento estatuiu as normas, que regulam até o presente momento, em todo o território nacional, a inspeção industrial e sanitária de produtos de origem animal e seus produtos, como a carne, leite, ovos, mel e pescados; desde a sua produção até a sua comercialização (BRASIL, 1952). Assim, os frigoríficos passaram a ter que cumprir normas de inspeção e fiscalização. O Serviço de Inspeção Federal (SIF) deve assegurar a segurança higiênico-sanitária e tecnológica dos produtos e subprodutos de origem animal. Além de regulamentar e controlar mercadorias de origem animal e animais vivos a serem exportadas. Os programas de controle têm como objetivo analisar a conformidade dos produtos de origem animal em relação aos aspectos microbiológicos e físico-químicos, propiciando assim, a avaliação do processo produtivo, com vistas à proteção do consumidor (MAPA, 2018).

As regras estabelecidas pela legislação brasileira tornaram os frigoríficos mais mecanizados e automatizados, para alcançar maior grau de perfeição, com especialização do maquinário, extensa divisão de tarefas, trabalho semiqualificado e produção relativamente homogênea em grande escala. Trouxeram igualmente, uma intensificação do trabalho e a ideia de eficiência técnica.

Este mecanismo de produção, capitalista é, essencialmente, produção de mais-valor. $O$ aumento da produtividade resulta, então, do mais-valor relativo que diz respeito à mecanização da produção. O trabalhador, por meio do aumento da força produtiva, é capaz de produzir mais no mesmo intervalo de tempo, provocando, assim, uma queda no valor da mercadoria individual (MARX, 2017). A tendência dos frigoríficos é a 
utilização de máquinas cada vez mais modernas para produzir mais por um preço menor, e assim extrair mais valor. Contudo, aumentando a exploração da força de trabalho direta ou indiretamente.

As máquinas elevam não apenas a produtividade como também a intensidade do trabalho. Elas aumentam a velocidade média das atividades desempenhadas pelos trabalhadores, com o objetivo de ampliar os resultados do trabalho, materializados nas mercadorias produzidas (DAL ROSSO, CARDOSO, 2015). Enquanto a produtividade refere-se à elevação dos resultados obtidos na produção, mediante avanços técnicos, a intensidade está ligada não só ao esforço físico, mas a todas as capacidades do trabalhador, corpo, mente, envolvimento pessoal e saberes adquiridos ou transmitidos pelo processo de socialização (DAL ROSSO, 2006). Porém, nem sempre o aumento de resultados pode significar crescimento da produtividade, pois esta pode conter e esconder a intensidade; "produtividade e intensidade são esferas distintas e como tal devem ficar separadas" (DAL ROSSO, 2008, p. 26).

Pina e Stoz (2014) chamam atenção para que a intensificação do trabalho não seja entendida, de forma simplificada, em termos de magnitude e/ou resultado. A intensificação está na exploração do trabalho, afetando diretamente o trabalhador, e é definida pelas

práticas específicas de exploração/expropriação tendentes a enfraquecer a capacidade coletiva do trabalhador, para proteger sua saúde e, principalmente, para questionar as determinações dos problemas e dos agravos à sua saúde (PINA, STOZ, 2014, p.159).

O processo de intensificação do trabalho nos frigoríficos é imanente ao seu modo de produção predominantemente taylorista e fordista (ANTUNES, 2014). A divisão do trabalho neste setor intensifica a exploração da força de trabalho. Disso resulta a constituição de um exército de trabalhadores mutilados, lesionados, adoecidos física e mentalmente, muitos deles incapacitados de forma definitiva para o trabalho (ANTUNES, PRAUN, 2015).

A organização do ponto de vista dos trabalhadores e sindicatos, levou a promulgação da Norma Regulamentadora (NR) 36, uma conquista de direitos para a categoria. Esta Norma sistematiza pontos relativos à saúde e segurança no trabalho em empresas de abate e processamento de carnes e derivados, que constam em outras NR da Portaria no 3.214 (BRASIL, 1978). Sua promulgação foi positiva pois estabelece os requisitos mínimos para a avaliação, controle e monitoramento dos riscos existentes nas atividades desenvolvidas nestas empresas. Leva em consideração os equipamentos e instrumentos de trabalho, o mobiliário, a velocidade e o ritmo de trabalho. Estabelece também a concessão de pausas aos trabalhadores e propõe o uso obrigatório de equipamentos de segurança e critérios relacionados às condições ambientais de trabalho e das plantas de abate e de processamento de carnes e seus derivados.

No entanto, a normatização do trabalho em frigoríficos ainda encontra limites pois apenas estabelecer regras não previne o desgaste do trabalhador, mas somente sustenta a apropriação da força de trabalho necessária para a acumulação de capital.

Harvey (2008, p.119) usa a expressão "modo de regulamentação" para se referir ao "tratamento dado aos problemas da organização da força de trabalho para propósitos de acumulação do capital em épocas e lugares particulares”. Já Praun (2016, p. 49) fala sobre "[... . estratégias de gestão que organizarão o trabalho na fábrica, impactando 
particularmente os laços de solidariedade construídos pelos trabalhadores [...]", chamados de colaboradores.

A sobrecarga gerada pelo processo de intensificação do trabalho contribui para o adoecimento dos trabalhadores do setor frigorífico, e que por sua vez, devido a alta produtividade gera mais intensificação do trabalho, criando assim, um ciclo vicioso (MAGRO, 2014).

A interação dinâmica entre os elementos existentes no processo de trabalho e o corpo do trabalhador gera adaptações e determina o desgaste dos trabalhadores como "transformações negativas, originadas pela interação dinâmica de cargas, nos processos biopsíquicos humanos" (LAURELL, NORIEGA, 1989, p. 109). Estes autores propõem as categorias analíticas de "cargas de trabalho" e de "desgaste" para a análise do processo de trabalho.

As cargas de trabalho são "elementos do processo de trabalho que interatuam dinamicamente entre si e com o corpo do trabalhador, gerando processos de adaptação que se traduzem em desgaste" (LAURELL, NORIEGA, 1989, p.110). Estão relacionadas não só à tecnologia implantada como à organização social e espacial do trabalho. Agrupadas em físicas, químicas, biológicas e mecânicas, as cargas possuem materialidade externa ao corpo, e com ele se interatuam; e fisiológicas e psíquicas, que apesar de não terem uma materialidade visível, se expressam em transformações biopsíquicas ou desgaste, por meio de um distúrbio ou doença (LAURELL, NORIEGA, 1989).

No ambiente de trabalho de frigorífico, há elementos de carga física, dos quais se destacam: ruído, vibrações, calor e frio, umidade e iluminação. Estes elementos ao interagirem com 0 corpo do trabalhador provocam processos complexos, desencadeando mecanismos de adaptação, tais como, irritação, sudorese, resfriado e reações alérgicas.

As cargas biológicas são as mais frequentes, uma vez que os trabalhadores estão expostos por contato direto aos materiais biológicos, como carne, sangue, secreções e outros; que podem conter agentes biológicos provenientes de doenças infecciosas.

As cargas mecânicas são derivadas dos instrumentos de trabalho e materiais que compõem o ambiente de trabalho, quando esses não recebem a devida manutenção, ou não são projetados e/ou instalados adequadamente e se convertem em lesões, como as contusões, as fraturas, as feridas - no caso de acidentes. Guindastes, passarelas, rampas, escadas e plataformas móveis e muito altas são os exemplos mais comuns encontrados na sala de abate.

As cargas fisiológicas podem ser decorrentes dos esforços visuais e físicos necessários à atividade, como: esforço físico intenso, posições incômodas e inadequadas; posições incômodas; trabalho estático com movimentação de partes do corpo; sobrecarga de atividades e horas extra.

As cargas psíquicas dizem respeito ao estresse no trabalho, consequentes do ritmo e da intensidade (SECCO, 2010). Como exemplo de cargas psíquicas existentes no trabalho em frigoríficos tem-se: repetitividade, trabalho em ritmo acelerado, atenção permanente e supervisão intensa.

Há uma articulação direta entre o processo saúde-doença e o processo de trabalho, distintos em relação ao grupo social em que se insere, a classe trabalhadora ou os 
donos dos meios de produção. Deste modo, a determinação do processo saúdedoença guarda uma relação direta com a concepção teórica do social, expresso em duas categorias básicas de análise, classe social e processo de trabalho em sua acepção materialista histórica (LAURELL, 1986).

Laurell (1986) destaca a necessidade de analisar os fenômenos de saúde e doença em um contexto econômico, político e ideológico da sociedade, e não somente como um fenômeno biológico. Através do entendimento do processo de trabalho compreendemos o caráter histórico e social do processo saúde-doença, já que 0 desenvolvimento das forças produtivas e das relações sociais de produção são responsáveis pelo desenvolvimento da sociedade.

\section{Conclusão}

Neste estudo observou-se que processo de intensificação é característico no setor da agroindústria, marcado pelo aumento da produtividade resultante da exploração capitalista. Isto permite tornar-se competitivo e expandir o mercado. $\mathrm{Na}$ estrutura de poder dominada pelo capital, a sua lógica de reprodução que coordena o modo de produção de toda a sociedade. Se produz para lucrar sem limites, pela exploração e desigualdade. $O$ processo de intensificação do trabalho dos frigoríficos ocorre pela divisão do trabalho presente nas linhas de produção, que é um conjunto de operações executadas por trabalhadores especializados onde cada um executa uma operação parcial e todas são executadas simultaneamente.

O episódio da "carne fraca" foi tratado pela imprensa como um escândalo da carne adulterada no Brasil envolvendo várias empresas. Uma operação que envolveu etapas a respeito de distorções na indústria da carne, com repercussão internacional. A partir disso, o Ministério da Agricultura trabalhou para melhorar a inspeção nas indústrias para que não houvesse consequências diretas nas exportações, que, de fato, não sofreu queda. O resultado concreto foi apenas a busca para a manutenção da cadeia produtiva e do agronegócio. Porém a questão da produção permaneceu invisível, ocultando o processo de trabalho. Isso é a expressão real da relação de exploração e acumulação do capital. Embora o Ministério Público e os sindicatos dos trabalhadores na indústria de alimentação mantenham esforços para estabelecer limites no trabalho em frigoríficos o modo capitalista de produção nas indústrias bloqueia avanços no sentido da emancipação da classe trabalhadora.

\section{REFERÊNCIAS}

ANTUNES, Ricardo. Desenhando a Nova Morfologia do Trabalho no Brasil. Estudos Avançados, São Paulo, v. 28, n.81, p.39-53, 2014.

ANTUNES, Ricardo; PRAUN, Luci. A sociedade dos adoecimentos no trabalho Serv. Soc. Soc., São Paulo, n. 123, p. 407-427, jul./set., 2015.

BOSI, Antonio de Pádua. Corpos feridos, trajetórias interrompidas pela agroindústria brasileira duas leituras a partir de Bertolt Brecht e Upton Sinclair. Varia História, Belo Horizonte, v. 30, n 53, p. 571-592, mai/ago., 2014 a.

BOSI, Antonio de Pádua. Uma história social comparada do trabalho em frigoríficos: Estados Unidos e Brasil (1880-1970). História e Perspectivas, Uberlândia, v. 27, n. 51, p. 277-311, jul./dez., 2014 b.

BRASIL. Ministério da Agricultura Pecuária e Abastecimento. Decreto no 9.013, de 29 de março de 2017. Regulamenta a Lei oㅜ 1.283, de 18 de dezembro de 1950, e a Lei oํ 7.889, de 23 de novembro de 1989, 
que dispõem sobre a inspeção industrial e sanitária de produtos de origem animal. Brasília: Diário Oficial da União, Seção 1, p.3, de 30 mar 2017.

BRASIL. Decreto n 30.691, de 29 de março de 1952. Aprova o novo Regulamento de Inspeção Industrial Sanitária dos Produtos de Origem Animal. Brasília: Diário Oficial da União, Seção 1, p.10785, de 07 jul 1952.

BRASIL. Decreto no 24.550, de 03 de julho de 1934. Aprova o Regulamento de Inspeção Federal de Carne e Derivados. Brasília: Diário Oficial da União, Seção 1, p.13881, de 11 jul 1934.

BRASIL. Decreto n²4.549, de 03 de julho de 1934. Aprova o Regulamento de Inspeção Federal de Leite e Derivados. Brasília: Diário Oficial da União, Seção 1, p.13913, de 11 jul 1934.

BRASIL. Lei no 1.283, de 18 de dezembro de 1950. Dispõe sobre a inspeção industrial e sanitária dos produtos de origem animal. Brasília: Diário Oficial da União, Seção 1, p.18161, de 19 dez 1950.

BRASIL. Portaria $n^{\circ} 3.214$, de 08 de junho de 1978. Aprova as Normas Regulamentadoras - NR - do Capítulo V, Título II, da Consolidação das Leis do Trabalho, relativas a Segurança e Medicina do Trabalho. Brasília: Diário Oficial da União, Seção 1- Parte I, p.10.423, 08 jun 1978.

BRASIL. Ministério da Agricultura, Pecuária e Abastecimento. Anuário dos programas de controle de alimentos de origem animal do DIPOA. Vol. 4. Brasília: MAPA, 2018.

BRASIL. Ministério do Planejamento, Desenvolvimento e Gestão. Instituto Brasileiro de Geografia e Estatística. Censo Agropecuário 2017. Resultados preliminares. Brasília: IBGE, 2017.

CARVALHO, Thiago Bernardino de. A Importância do Brasil na Produção Mundial de Carne Bovina. Centro de Estudos Avançados em Economia Aplicada. São Paulo, 2018. Disponível em: https://www.cepea.esalq.usp.br/br/opiniao-cepea/a-importancia-do-brasil-na-producao-mundial-de-carnebovina.aspx. Acesso em: 28 dez. 2018.

DAL ROSSO, Sadi. Intensidade e imaterialidade do trabalho e saúde. Trab. educ. saúde, Rio de Janeiro, v. 4, n. 1, p. 65-92, mar., 2006.

DAL ROSSO, Sadi. Mais trabalho! A intensificação do labor na sociedade contemporânea. São Paulo: Boitempo, 2008.

DAL ROSSO, Sadi; CARDOSO, Ana Cláudia Moreira. Intensidade do trabalho: questões conceituais e metodológicas. Rev Sociedade e Estado, Brasília, v. 30, n. 3, p. 631-650, set/dez., 2015.

DELGADO, Guilherme Costa. Especialização primária como limite ao desenvolvimento. Desenvolvimento em Debate, Rio de Janeiro, v.1, n. 2, p.111-125, jan/abr e mai/ago., 2010.

DIAS, Juliana Vergueiro Gomes. O rigor da morte: a construção simbólica do "animal de açougue" na produção industrial brasileira. 2009. Dissertação (Mestrado em Antropologia Social), Instituto de Filosofia e Ciências Humanas da Universidade Estadual de Campinas, Campinas, 2009.

ENGELS, Friedrich. Do socialismo utópico ao socialismo científico. São Paulo: Edipro do Bolso, 2011.

FEDERICI, Silvia. Calibã e a Bruxa: mulheres, corpo e acumulação primitiva. São Paulo: Elefante, 2017.

FOOD AND DRUG ADMINISTRATION (FDA). History of FDA's Internal Organization. Disponível em: https://www.fda.gov/AboutFDA/History/FOrgsHistory/EvolvingPowers/ucm054819.htm. Acesso em: 29 dez. 2018.

FITZGERALD, Amy J. A Social History of the Slaughterhouse: From Inception to Contemporary Implications. Human Ecology Review, Fairfax, v. 17, n. 1, p.58-69, 2010.

HARVEY, David. Condição pós-moderna. São Paulo: Loyola, 2008.

LAURELL, Asa Cristina. El estudio social del proceso salud-enfermedad en América Latina. Cuadernos Médicos Sociales, Rosario, n 37, sep, p.1-10, 1986.

LAURELL, Asa Cristina; NORIEGA, Mariano. Processo de produção e saúde: trabalho e desgaste operário. São Paulo: Hucitec, 1989.

MARX, Karl; ENGELS, Friedrich. A ideologia alemã: crítica da mais recente filosofia alemã em seus representantes Feuerbach, B. Bauer e Stirner, e do socialismo alemão em seus diferentes profetas (18451846). São Paulo: Boitempo, 2007. 
MAGRO, Márcia Luíza Pit Dal; COUTINHO, Maria Chalfin; et al. Intensificação e prolongamento da jornada de trabalho nas indústrias de abate e processamento de carnes e seus impactos na saúde dos trabalhadores1. Cad. Psicologia Social do Trabalho, São Paulo, v. 17, n. 1, p. 67-83, jun. 2014.

MARX, Karl. Prefácio à Contribuição à Crítica da Economia Política. São Paulo: Expressão Popular, 2008

MARX, Karl. O Capital. Crítica da economia política. Livro 1. O processo de produção do capital. $2^{\circ}$ ed. São Paulo: Boitempo, 2017.

MARX, Karl. Grundisse. São Paulo: Boitempo, 2011.

MOREIRA, Maria Eunice. Charqueadas e Xarqueada: a vida saladeiril na província gaúcha. Letrônica. Porto Alegre, v. 42, n. 2, p. 161-172, jun. 2007.

PARDI, Miguel Cione. Memória da Inspeção Sanitária e Industrial de Produtos de Origem Animal no Brasil: O Serviço de Inspeção Federal - SIF. Depoimento para a História da Medicina Veterinária do Brasil. Tomo I. Serviço Público Federal. Conselho Federal de Medicina Veterinária. Brasília: Columbia, 1996.

PINA, José Augusto; STOTZ, Eduardo Navarro. Intensificação do trabalho e saúde do trabalhador: uma abordagem teórica. Rev. Bras. Saúde Ocup., São Paulo, v. 39, n. 130, p. 150-160, 2014.

PRAUN, Luci. Reestruturação produtiva, saúde e degradação do trabalho. Campinas: Papel Social, 2016.

RIFKIN, Jeremy. Beyond Beef: the rise and fall of the cattle culture. New York: Dutton, 1992.

SANTOS, Luciana da Silva. Terceiro Distrito, carne verde e matadouro: um Triângulo bem articulado na primeira capital republicana (Rio de Janeiro, final do século XIX). Rev Catarinense de História, Florianópolis, n.19, p.73-94, 2011.

SECCO, lara Aparecida de Oliveira; ROBAZZI, Maria Lúcia do Carmo Cruz; et al. Cargas psíquicas de trabalho e desgaste dos trabalhadores de enfermagem de hospital de ensino do Paraná, Brasil. SMAD Rev. Eletrônica Saúde Mental Álcool Drog., Ribeirão Preto, v. 6, n. 1, p. 1-17, 2010.

SHINYASHIKI, Clarice Barbieri; SOUZA, Érica Christina Rodrigues; SALGADO, Ivone. Obras públicas da cidade de São Paulo na metade do século XIX: o higienismo e a construção do cemitério público, do mercado público e do matadouro público. In: ANPUH XXIV Simpósio Nacional de História. São Leopoldo: Associação Nacional de História 2007. Disponível em: http://snh2007.anpuh.org/resources/content/anais/lvone\%20Salgado\%20lll.pdf. Acesso em: 27 dez 2018.

SINCLAIR, Upton. The Jungle. Bantam Los Angeles: Classic, 1981.

Data de submissão: 20/06/2019

Data de aprovação: 31/08/2019 